Article

\title{
Effect of Repetitive Collar Replacement on the Residual Strength and Fatigue Life of Retained Hi-Lok Fastener Pins
}

\author{
David F. Hardy ${ }^{\dagger}$ and David L. DuQuesnay * \\ Department of Mechanical and Aerospace Engineering, Royal military College of Canada, PO Box 17000 Station \\ Forces, Kingston, ON K7K 7B4, Canada; David.Hardy@forces.gc.ca \\ * Correspondence: duquesnay-d@rmc.ca; Tel.: +613-541-6000 (ext. 6483) \\ + Currently: DT4 Structural Engineer, Aerospace Telecommunications and Engineering Support Squadron, \\ K0K 3W0 Astra, ON, Canada.
}

Received: 13 March 2019; Accepted: 9 April 2019; Published: 16 April 2019

\begin{abstract}
Hi-Lok fasteners were subjected to multiple collar replacements, and were tested under static loading and constant-amplitude fatigue loading, to determine the effect of repetitive collar replacement on the residual strength and fatigue life of a retained Hi-Lok-type fastener pin. Hi-Lok-type fasteners are typically used in aircraft structural joints, and are loaded mainly in shear. Tests were conducted for clamping force, static shear strength, static tensile strength, and shear fatigue life for collars subjected to five collar replacements. The static shear results showed no decrease in the ultimate shear strength of the fastener pin as a function of collar replacement. Static tensile results showed no decrease in the ultimate tensile strength of the fastener as a function of collar replacement, with failure of the aluminum collar remaining the critical failure mode. Similarly, shear fatigue results showed no decrease in the shear fatigue life of the fastened joint as a result of collar replacement, with fracture of the aluminum substrate remaining the critical failure mode. For static shear, static tension, and shear fatigue tests, estimated clamping force was highly consistent between specimens and no decrease in clamping force was observed as a function of collar replacement.
\end{abstract}

Keywords: aircraft; fatigue; fastener; reuse

\section{Introduction}

Hi-Lok-type [1] fasteners are used extensively in the aerospace industry, and consist of a threaded fastener pin and collar. The threaded collar includes a wrenching element that shears-off at a fixed torque, enabling rapid installation while ensuring a consistent pre-load for each fastener. The manufacturer's installation instructions recommend retention and reuse of undamaged Hi-Lok fastener pins following collar removal [2]; however, current Royal Canadian Air Force (RCAF) maintenance procedures [3] call for the replacement of an installed aircraft Hi-Lok fastener pin each time the collar is removed.

Despite this current practice, it may be preferable from an aircraft maintenance standpoint to remove and replace the collars without replacing the installed fastener pins in some instances. Specifically, retention of the installed pins may be preferable when accessing fastener holes for Non-Destructive Inspection (NDI) of aircraft structure using techniques such as Eddy Current Surface Scan (ECSS). NDI necessitating scheduled collar removal is often carried out in structural areas where fatigue cracking is a concern. By far, the most commonly used technique to detect fatigue damage in and around aircraft fasteners involves eddy current (EC) inspection. Fhar and Wallace [4] provide a comprehensive discussion of various NDI techniques used to inspect fastener holes in aircraft structures. The most common and reliable method is the bolt hole eddy current (BHEC) that requires the removal of the fastener itself to permit a probe into the faster hole for inspection. However, the removal and 
re-installation of interference fit fastener pins causes mechanical damage to the fastener hole due to strain and physical abrasion. It is clear that repetitive removal and installation of interference fit fastener pins throughout the life of the aircraft will produce far more mechanical damage than if the initial fastener pin were retained. Thus, ironically, the periodic removal and reinstallation of interference fit fastener pins for NDI of fatigue-prone areas risks exacerbating the existing fatigue concerns at these locations by generating or aggravating existing crack initiations. Although not as powerful as BHEC at detecting cracks, especially cracks within the bore of faster hole, ECSS can still be used to detect surface cracks. The removal of the fastener collar enables detection of cracks at the edge of the fastener hole, rather than only detecting cracks that extend past the edge of the installed collar. It has been shown that fatigue crack growth in aircraft structure under a variety of loading conditions follows an exponential growth rate with usage (cycles or flights) with the majority of fatigue lifetime spent with cracks relatively small, approximately $5 \mathrm{~mm}$ or less [5]. Because of the exponential nature of crack growth, the ability to detect fatigue cracks while they remain relatively short significantly increases the allowable time between inspections, considerably reducing manpower requirements and maintenance downtime for the affected aircraft fleet.

The replacement of fastener collars for NDI without the removal of the interference fit fastener pins may therefore help to maximize the fatigue life of the aircraft structure being inspected. An example of a structural area where repetitive collar replacement was considered for use in the RCAF is shown in Figure 1 for Critical Point 16 on the CP140 Aurora [6]. Selected hardware, test specimens, and applied loads for this project were based on the fasteners and structure at this location. Although the fatigue behavior of fasteners and joints in aircraft structure has been studied extensively [5,7], only a few studies have been done on the effect of repeated re-installation of fasteners. Li and Su [8] studied the effect of repeatedly tightening and loosening the nut on titanium fasteners in a carbon fibre composite structure. They found that the clamping load decreased rapidly with repeated loosening-tightening cycles with a drop in clamp load between 66-76\% within five repetitions and down to about $45 \%$ after 15 repetitions. Clamping load is critical to the fatigue performance of typical fastened aircraft structural joint, with a decrease in clamping load leading to early fatigue failure [7].

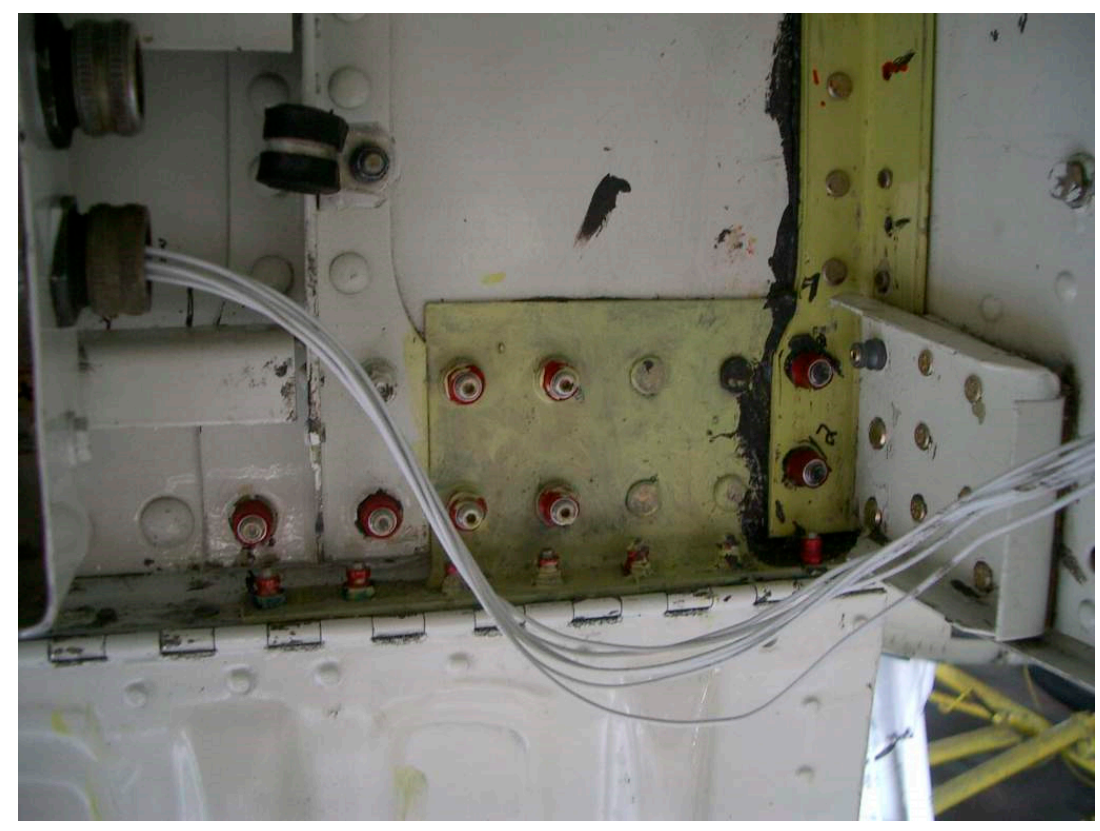

Figure 1. CP140 Critical Point 16 inboard engine nacelle skate angle.

Despite the current RCAF practice of replacing fastener pins and collars at each inspection, it is evident that there is a benefit, and it would be convenient, to retain the faster pins in some situations while removing only the collar to allow clear access to the fastener hole for inspection. The effect of 
repeated replacement of the collar on Hi-Lok pins on the subsequent strength and life of the fastener, and on the clamping load has not yet been reported. The aim of this research was to determine the effect of repetitive collar replacement on the residual clamping force, static strength, and fatigue life of retained Hi-Lok-type fastener pins. Fasteners were tested separately in both tension and shear to determine their behaviour under each primary loading condition. The results of this study will provide some evidence to support the practice of repeated collar replacements on retained Hi-Lok fasteners in aircraft structure where pin removal would be difficult, as is the case for Critical Point 16 on the CP140 Aurora [6].

\subsection{Equivalent Interference Fits}

Most aerospace applications of Hi-Lok-type fasteners use interference fits between the pins and fastener holes to generate localized compressive stresses that reduce crack growth rates, improving the fatigue life of the component. Critical Point 16 on the CP140 Aurora is taken as a representative example of a fatigue-prone aircraft structure where Hi-Lok-type fasteners are employed. This location calls for $0.245^{\prime \prime}$ to $0.248^{\prime \prime}(6.22 \mathrm{~mm}$ to $6.30 \mathrm{~mm})$ diameter fastener holes $[9,10]$ in the 7075 -T6 aluminum structure to accommodate $0.249^{\prime \prime}(6.32 \mathrm{~mm})$ diameter steel fastener pins, resulting in an interference of $0.001^{\prime \prime}$ to 0.004 " $(0.025 \mathrm{~mm}$ to $0.100 \mathrm{~mm})$ between the pins and the substrate.

In order to generate an equivalent amount of physical interference and resultant mechanical damage in the test specimens for this project, $0.245^{\prime \prime}(6.22 \mathrm{~mm})$ diameter reamed fastener holes were used for all aluminum shear test fixtures. Because strength and fatigue requirements resulted in some of the test specimens, such as the tensile test jigs, being manufactured from high-strength steel, the physical interference of fastener holes in the steel test fixtures is reduced to ensure a similar level of mechanical damage to the fastener pin during installation. When determining the appropriate level of interference fit, it is assumed that the mechanical damage to the pin during installation is proportional to its radial strain.

For the aluminum plates in the shear test fixtures, total deformation at the fastener hole, $\Delta D_{\text {total }}$, is equal to the difference between the diameters of the fastener pin, $D_{\text {pin }}$, and fastener hole, $D_{\text {hole }}$ :

$$
\Delta D_{\text {total }}=D_{\text {pin }}-D_{\text {hole }}
$$

Part of this deformation is caused by negative strain (radial compression) of the pin, while the remainder is accommodated by positive strain (radial expansion) of the fastener hole.

The deformation of the pin can be expressed in terms of the deformation of the fastener hole, knowing that the relative strains of these components will be directly proportional to the relative stiffness of the pin and plate materials:

$$
\begin{gathered}
\frac{\left|\varepsilon_{\text {pin }}\right|}{\varepsilon_{\text {hole }}}=\frac{E_{\text {plate }}}{E_{\text {pin }}}, \\
\frac{E_{\text {plate }}}{E_{\text {pin }}}=\frac{\left(\frac{\left|\Delta D_{\text {pin }}\right|}{D_{\text {pin }}}\right)}{\left(\frac{\Delta D_{\text {hole }}}{D_{\text {hole }}}\right)}, \\
=\frac{D_{\text {hole }}\left|\Delta D_{\text {pin }}\right|}{D_{\text {pin }} \Delta D_{\text {hole }}}, \\
\left|\Delta D_{\text {pin }}\right|=\frac{D_{\text {pin }} \Delta D_{\text {hole }}}{D_{\text {hole }}}\left(\frac{E_{\text {plate }}}{E_{\text {pin }}}\right),
\end{gathered}
$$

where $\left|\varepsilon_{\text {pin }}\right|$ is the absolute radial strain of the pin (by convention, compressive strain will have a negative value),

$\varepsilon_{\text {hole }}$ is the radial strain of the fastener hole,

$E_{\text {pin }}$ is the elastic modulus of the HL51-8-6 fastener pin material, $2.9 \times 10^{4} \mathrm{ksi}$ (199 GPa) [11], 
$E_{\text {plate }}$ is the elastic modulus of the 7075-T6 plate material, $1.03 \times 10^{4} \mathrm{ksi}$ (70 GPa) [11],

$\left|\Delta D_{\text {pin }}\right|$ is the absolute radial deformation of the pin (compressive deformation will have a negative value), and

$\Delta D_{\text {hole }}$ is the radial deformation of the fastener hole.

Substitute Equation (1) into Equation (2) and solve for the deformation of the pin:

$$
\left|\Delta D_{\text {pin }}\right|=\Delta D_{\text {total }}\left(\frac{A}{1+A}\right)
$$

where $A=\frac{D_{\text {pin }} E_{\text {plate }}}{D_{\text {hole }} E_{\text {pin }}}$.

Calculating deformation of the fastener pin in the aluminum plates:

$$
\begin{gathered}
\Delta D_{\text {total }}=D_{\text {pin }}-D_{\text {hole }}=(0.249)-(0.245)=0.004^{\prime \prime}(0.100 \mathrm{~mm}), \\
A=\frac{D_{\text {pin }} E_{\text {plate }}}{D_{\text {hole }} E_{\text {pin }}}=\frac{(0.249)\left(1.03 \times 10^{4}\right)}{(0.245)\left(2.90 \times 10^{4}\right)}=0.36 \\
\left|\Delta D_{\text {pin }}\right|=\Delta D_{\text {total }}\left(\frac{A}{1+A}\right)=4.00 \times 10^{-3}\left(\frac{0.36}{1+0.36}\right)=0.001^{\prime \prime}(0.025 \mathrm{~mm}) .
\end{gathered}
$$

Because aluminum has a much lower elastic modulus than steel, aluminum test jigs will have a greater amount of deformation relative to the steel fastener pin than steel test jigs, assuming equal dimensions. In order to ensure the same level of mechanical damage for the fastener pins in the steel axial test jig, radial strain (and therefore radial deformation) of the fastener pin is held constant.

To find the interference fit that will generate the same radial deformation of the pin in a high-strength steel fixture, Equation (2) is solved for deformation of the fastener hole:

$$
\begin{aligned}
& \left|\Delta D_{\text {pin }}\right|=\frac{D_{\text {pin }} \Delta D_{\text {hole }}}{D_{\text {hole }}}\left(\frac{E_{\text {plate }}}{E_{\text {pin }}}\right), \\
& \Delta D_{\text {hole }}=\frac{D_{\text {hole }}\left|\Delta D_{\text {pin }}\right|}{D_{\text {pin }}}\left(\frac{E_{\text {pin }}}{E_{\text {plate }}}\right) .
\end{aligned}
$$

Rearranging Equation (1), the initial diameter of the fastener hole is equal to:

$$
D_{\text {hole }}=\left|\Delta D_{\text {pin }}\right|-\Delta D_{\text {total }} \text {. }
$$

Because the initial fastener hole diameter and radial deformation of the fastener hole are interdependent, the equations above are iterated for increasing values of $D_{\text {hole }}$ until a solution converges. For a defined absolute pin deformation of $0.0011 "(0.027 \mathrm{~mm})$ :

$D_{\text {hole }}=0.247^{\prime \prime}(6.30 \mathrm{~mm})$.

A $0.247^{\prime \prime}$ diameter $(6.30 \mathrm{~mm})$ reamed fastener hole was therefore used for the high-strength steel test fixtures.

\subsection{Measurement of Clamping Force}

Clamping force or "preload" is a major consideration for fastened joints. The application of a tensile preload to a fastener pin improves the fatigue life of the pin and the joint by decreasing the effective stress amplitude. Estimation of the clamping force in a fastened joint is therefore an important metric when assessing the impact of repetitive collar replacement on a retained fastener pin. 
The tightening torque, $T_{\text {on }}$, of a fastener can be related to the induced clamping force, $F$, by the following expression described by Eccles [12,13]:

$$
T_{\text {on }}=\frac{F}{2}\left[\frac{\mu_{t} d_{2}}{\cos \beta}+\frac{p}{\pi}+D_{e} \mu_{n}\right]
$$

where $\mu_{t}$ is the coefficient of friction for the thread;

$d_{2}$ is the basic pitch diameter of the thread;

$\beta$ is the half-included angle of the threads ( $30^{\circ}$ for UNF threads);

$p$ is the pitch of the threads;

$\mu_{e}$ is the coefficient of friction for the nut face; and

$D_{e}=\frac{1}{2}\left(d_{i}+d_{0}\right)$ is the effective bearing diameter of the nut,

where $d_{i}$ and $d_{o}$ are the inner and outer bearing diameters of the nut, respectively.

The loosening torque, $T_{\text {off, }}$ can similarly be related to the clamping force by the expression:

$$
T_{o f f}=\frac{F}{2}\left[\frac{\mu_{t} d_{2}}{\cos \beta}-\frac{p}{\pi}+D_{e} \mu_{n}\right]
$$

From these equations, the difference between the tightening and loosening torques can be simplified into the following expression:

$$
T_{o n}-T_{o f f}=F\left(\frac{p}{\pi}\right)
$$

Rearranging Equation (8), the clamping force in the joint can be simply related to the difference between the tightening and loosening torques, as follows:

$$
F=\frac{\pi}{p}\left(T_{o n}-T_{o f f}\right)
$$

The uncertainty of clamping force estimates calculated using this method varies depending on the method of torque application, but is generally found to fall within $\pm 17 \%$ using a precision torque wrench [7].

While Eccles $[12,13]$ recommends the use of an on-off-on measurement process to record tightening and loosening torques for the fastener, this process is not practical for Hi-Lok-type collars. Because the wrenching element of the collar torques-off at a pre-determined torque during installation, subsequent tightening of the collar is not easily achieved and is difficult to measure accurately. Moreover, loosening of the collar can only be achieved and accurately measured by damaging means, using specialized Hi-Lok removal tools. For the purposes of this experiment, tightening torque, $T_{\text {on }}$, is therefore assumed to be equal to the peak torque achieved during installation of the collar. Loosening torque, $T_{\text {off }}$, is taken as the peak torque achieved during removal of the collar.

\section{Materials and Methods}

The fasteners used in this project are the Hi-Lok HL51-8-6 (HL19 equivalent) 0.25" (6.35 mm) diameter $100^{\circ}$ flush shear head cadmium-plated alloy steel fastener pins with HL70-8 aluminum collars. These are the countersunk fastener type used on the CP140 Aurora at Critical Point 16, and are used extensively on CP140 and CC130 aircraft. Moreover, these alloy steel flush shear head fasteners are broadly representative of similar Hi-Lok-type fasteners used across many other RCAF aircraft fleets. This type of fastener is designed and intended to take shear loading. The specified mechanical properties of the fasteners and collars are given in Tables 1 and 2, respectively. 
Table 1. Mechanical properties of HL51-8-6 fastener pin [11].

\begin{tabular}{ccc}
\hline Property & Value (as Specified) & Value (SI Equivalent) \\
\hline Shaft diameter, $D$ & $0.249 \pm 0.010^{\prime \prime}$ & $6.32 \pm 0.025 \mathrm{~mm}$ \\
Grip Length, $L$ & $0.375 \pm 0.005^{\prime \prime}$ & $9.52 \pm 0.127 \mathrm{~mm}$ \\
Thread & $0.250-28$ UNJF-3A & - \\
Material & Alloy Steel & - \\
Surface Treatment & Cadmium & $199 \mathrm{GPa}$ \\
Elastic Modulus & $29,000 \mathrm{ksi}$ & $\geq 20.7 \mathrm{kN}$ \\
Ultimate Single Shear Strength, $P_{s u}$ & $\geq 4650 \mathrm{lb}_{\mathrm{f}}$ & $\geq 16.5 \mathrm{kN}$ \\
Ultimate Tensile Strength, $P_{t u}$ & $\geq 3700 \mathrm{lb}_{\mathrm{f}}$ & $\geq 654 \mathrm{MPa}$ \\
Ultimate Shear Stress, $F_{s u}$ & $\geq 95 \mathrm{ksi}$ & $1100-1240 \mathrm{MPa}$ \\
Ultimate Tensile Stress, $F_{t u}$ & $160-180 \mathrm{ksi}$ &
\end{tabular}

Table 2. General properties of HL70-8 collar [14].

\begin{tabular}{ccc}
\hline Property & Value (as Specified) & Value (SI Equivalent) \\
\hline Outer Diameter, $D$ & $0.249 \pm 0.010^{\prime \prime}$ & $6.32 \pm 0.025 \mathrm{~mm}$ \\
Retained Length, $L\left(^{*}\right)$ & $0.375 \pm 0.005^{\prime \prime}$ & $9.52 \pm 0.127 \mathrm{~mm}$ \\
Thread & $0.250-28 \mathrm{UNJF}-3 \mathrm{~B}$ & - \\
Material & $2024-\mathrm{T} 6$ Aluminum & - \\
Ultimate Tensile Strength, $P_{t u}$ & $\geq 3000 \mathrm{lb}_{\mathrm{f}}$ & $13.3 \mathrm{kN}$ \\
Torque (on installation) & $60-80 \mathrm{lb}_{\mathrm{f}}-\mathrm{in}$ & $6.78-9.04 \mathrm{Nm}$ \\
\hline
\end{tabular}

* Length after torque-off of wrenching element.

Fasteners were installed and removed using a DTL-100i Digital Torque Wrench and compatible 3/8" socket, an Allen key, and SAVI-32, -34, and -36 Hi-Lok removal tools.

\subsection{Procedures}

Unless otherwise shown, ten repetitions of each specimen type were tested to generate statistically significant results. All shear test specimens were made with the same dimensions, consisting of two strips of material measuring $1.50^{\prime \prime} \times 4.50^{\prime \prime} \times 0.125^{\prime \prime}(38.1 \mathrm{~mm} \times 114 \mathrm{~mm} \times 3.17 \mathrm{~mm})$ with a single fastener installed in the overlap. An edge distance, $e=0.50^{\prime \prime}(12.7 \mathrm{~mm})$ was used for all fastener holes. This edge distance is reflective of typical aircraft structure and allows direct comparison with manufacturers' material strength values, which are typically quoted for edge distances of 2D or greater.

\subsection{Baseline Static Shear}

Fasteners were installed in accordance with [3] into single-fastener lap joints made from AISI Type $\mathrm{O} 1$ steel plates and tested monotonically to failure. The test fixture is illustrated in Figure 2. The ultimate shear strength and failure mode were recorded for each specimen.

\subsection{Static Shear with Collar Replacement}

Following completion of the baseline tests, static shear tests were conducted on fasteners subjected to multiple collar replacements. Fasteners were installed in accordance with [3] into single-fastener interference fit lap joints made from 7075-T6 aluminum sheet. Collars were removed and re-installed in accordance with [3] for a total of five collar replacements. The loosening and tightening torques for all collars were measured using a digital torque wrench to enable calculation of the clamping force of each collar in accordance with [11]. Following the fifth and final collar replacement, the fastener pins were removed from the aluminum plate specimens and installed with a clearance fit in accordance with [3] into heat treated AISI Type O1 steel sheet (Figure 2), which provided the high strength required for shear testing of the fastener pins. In an aircraft inspection scenario, the possibility of damaging the substrate material would be a major concern, but, in our case, damage to the fastener pin was of interest. The pins were carefully pressed out in a single continuous motion and then visually inspected under 
light microscope (up to $20 \times$ ). No discernable damage was visible on any fastener shank. The fasteners were then tested monotonically to failure to determine the ultimate shear strength and failure mode for each specimen.

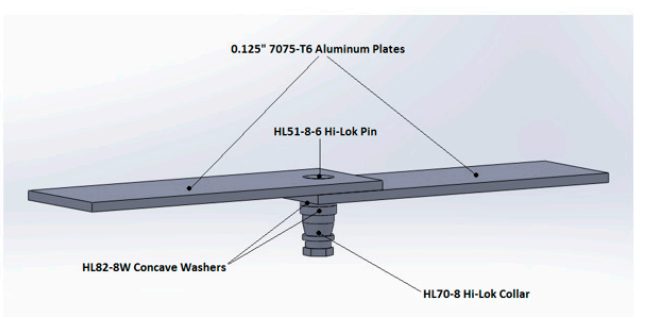

(a)

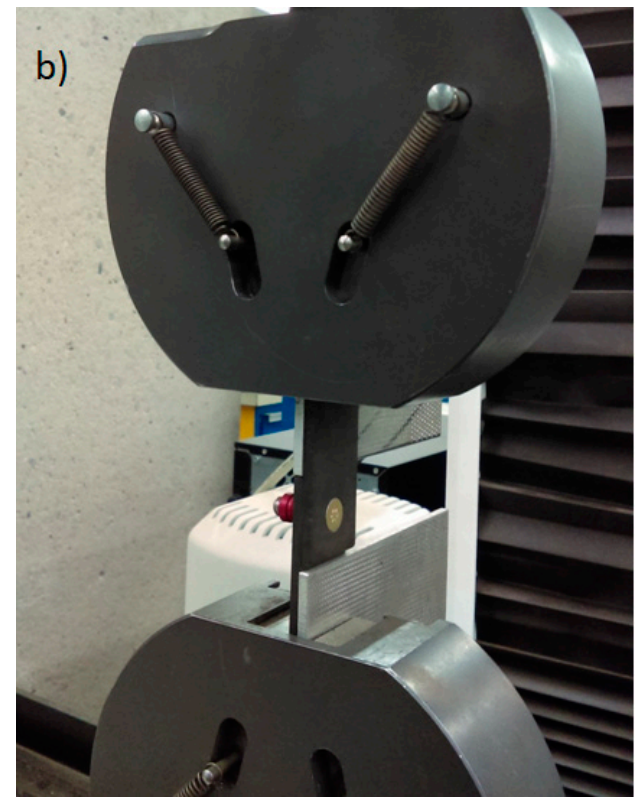

Figure 2. Static shear test assembly (a) aluminum joint for repeated collar installation and (b) steel shear test fixture installed in test machine.

\subsection{Static Tension}

Tests were conducted to determine the baseline ultimate tensile strength of the fasteners with no collar replacement. The fasteners were installed in accordance with [3] into an SAE4340 steel tensile test fixture and tested monotonically to failure. This test fixture is illustrated in Figure 3. The ultimate tensile strength and failure mode was recorded for each specimen.
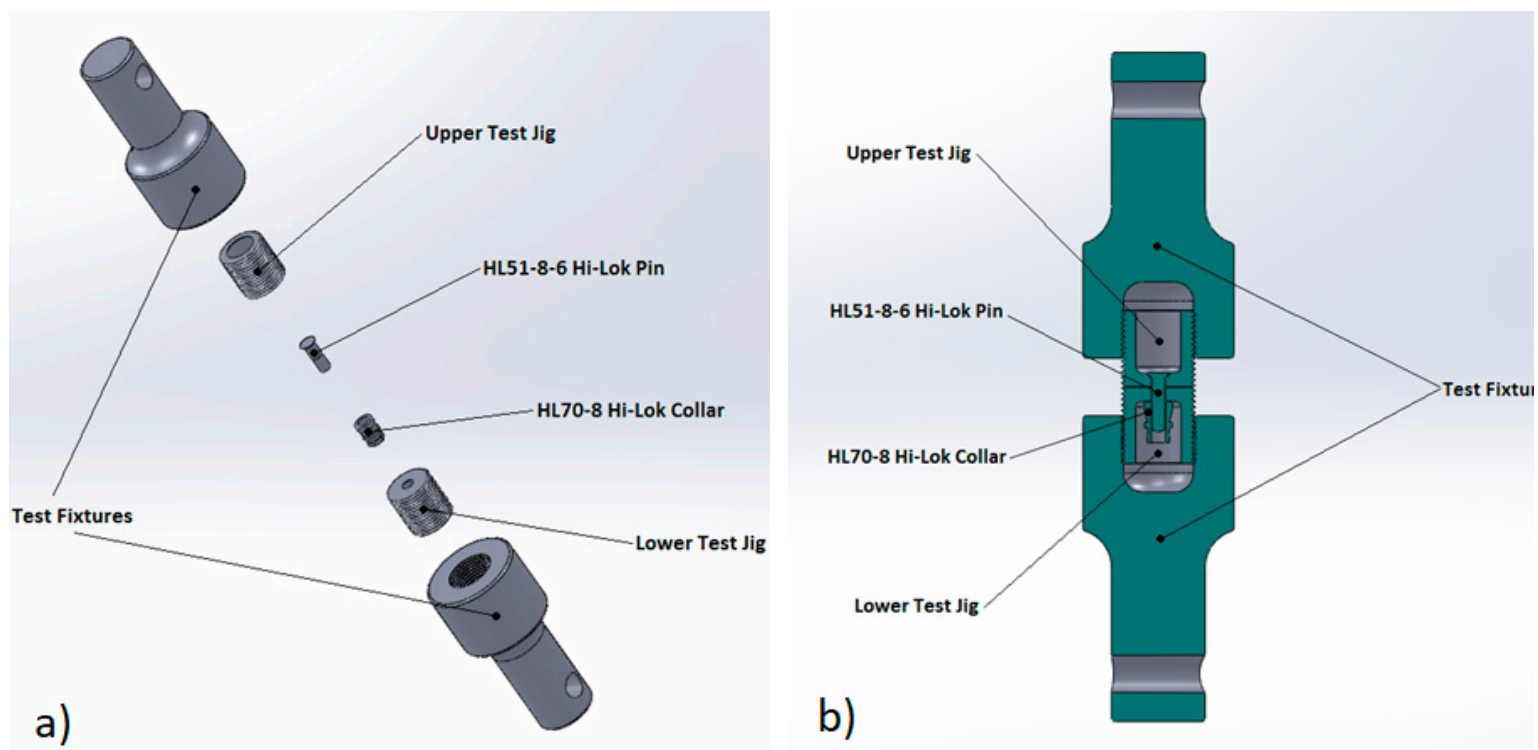

Figure 3. Static tension test assembly (a) exploded view and (b) cross section of the assembly. 


\subsection{Static Tension with Collar Replacement}

Following completion of the baseline tests, static tensile tests were conducted on fasteners subjected to multiple collar replacements. Collars were removed and re-installed in accordance with [3] for a total of five collar replacements. The loosening and tightening torques for all collars are measured using a digital torque wrench to enable calculation of the clamping force of each collar in accordance with [11]. Following the fifth and final collar replacement, the Hi-Lok fasteners were tested monotonically to failure to determine the ultimate tensile strengths and critical failure modes for each specimen.

\subsection{Baseline Shear Fatigue}

Tests were conducted to calibrate load levels and determine the baseline fatigue life for the specimens with no collar replacement. The fasteners were installed in accordance with [3] into single-fastener lap joints made from 7075-T6 aluminum sheet. The assembled specimens were installed into a servo-hydraulic test system and subjected to constant-amplitude loading with a load ratio, $R=0$ and a maximum shear fatigue load of $900 \mathrm{lb}_{\mathrm{f}}(4.0 \mathrm{kN})$ based on the allowable shear load for these fasteners ${ }^{4}$, calibrated to obtain an average fatigue life of around 500,000 cycles. Shear fatigue test specimens used the configuration shown in Figure 2a. Installed and failed specimens are shown in Figure 4.

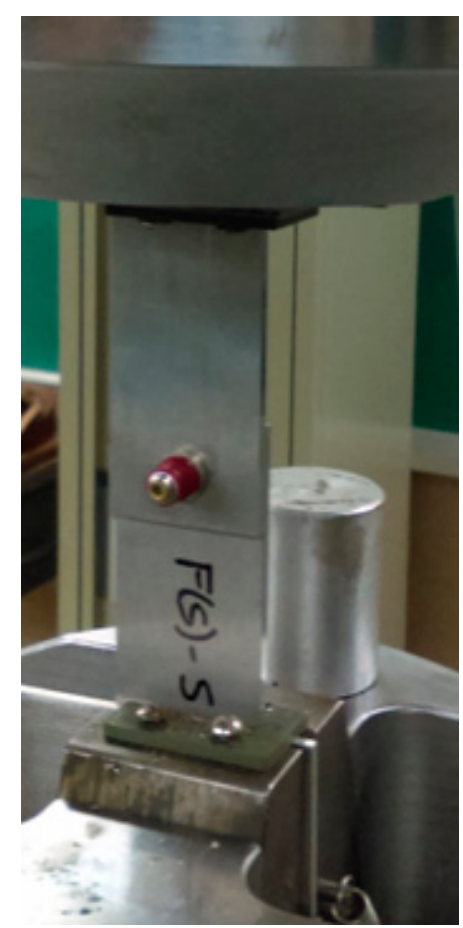

(a)

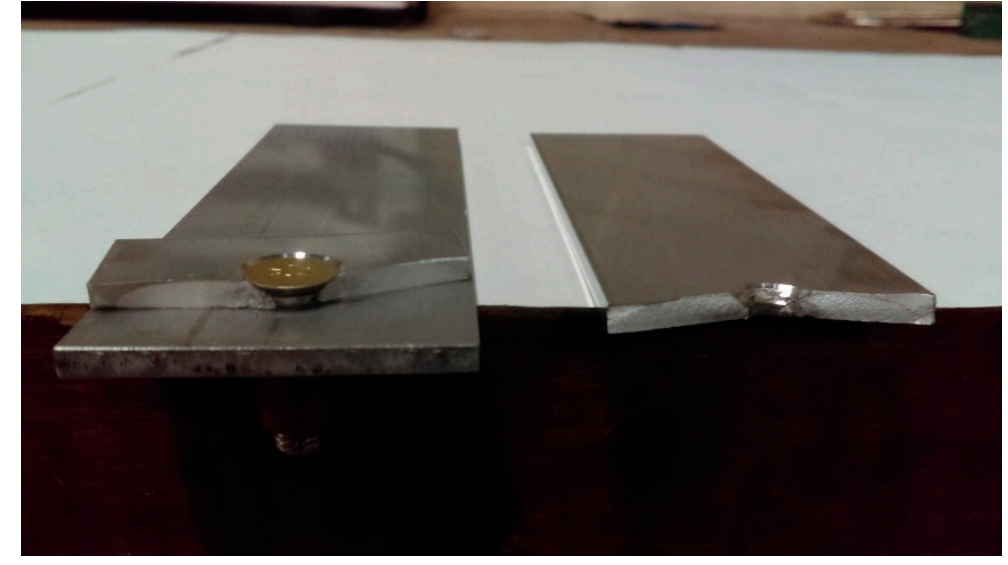

(b)

Figure 4. Shear fatigue test specimen (a) loaded in test frame and (b) failed in fatigue.

\subsection{Shear Fatigue with Collar Replacement}

Following completion of the baseline tests, shear fatigue tests were conducted on specimens subjected to multiple collar replacements. Fasteners were installed in accordance with [3] into single-fastener lap joints made from 2 overlapping strips of 7075-T6 aluminum sheet. The test fixture is illustrated in Figure 4a. The assembled specimens were installed into a servo-hydraulic test system and subjected to a constant-amplitude shear fatigue load, as calibrated during the baseline fatigue tests. The Hi-Lok collars were removed and re-installed in accordance with [3] after a fixed number of load cycles. The baseline fatigue tests gave a mean fatigue life of approximately 560,000 cycles with a standard deviation of 0.159 on logarithmic fatigue life. Assuming log-normal distribution of 
fatigue life values, the $98 \%$ confidence level occurs at roughly 2 standard deviations below the mean life, or approximately 250,000 cycles. This was considered to be the "service life" of the joint. Hence, the experimental shear fatigue test specimens were subjected to five collar changes at intervals of 45,000 cycles, based on the lower $98 \%$ confidence interval of the baseline fatigue life.

The loosening and tightening torques for all collars were measured using a digital torque wrench to enable calculation of the clamping force of each fastener in accordance with [11].

\subsection{Statistical Analysis}

In order to assess and quantify experimental differences between test specimens, simple statistical analysis was applied to the results. Welch's t-tests were performed to assess the statistical significance of any differences in static strength and fatigue life between baseline and experimental test specimens. Where multiple samples were assessed against each other, such as for the analysis of clamping force results, single-factor Analysis of Variance (ANOVA) was carried out to determine the statistical significance of any differences between sample means. In both cases, probability values were calculated to determine the statistical likelihood of having obtained the observed results through random statistical distribution within the sample.

\section{Results}

The experimental data collected in this study are included in tabulated form in Appendix A.

\subsection{Static Shear Strength}

For the static shear tests, nine baseline specimens and ten experimental specimens were tested to failure. Baseline and repeated collar replacement test results for static shear strength are compared in Figure 5a. All measured shear strengths exceed the published shear strength of $4650 \mathrm{lb}_{\mathrm{f}}(20.7 \mathrm{kN})$ for the HL19-8-6 fastener pin [13]. All test specimens failed in shear of the fastener pin, as shown in Figure 5b.
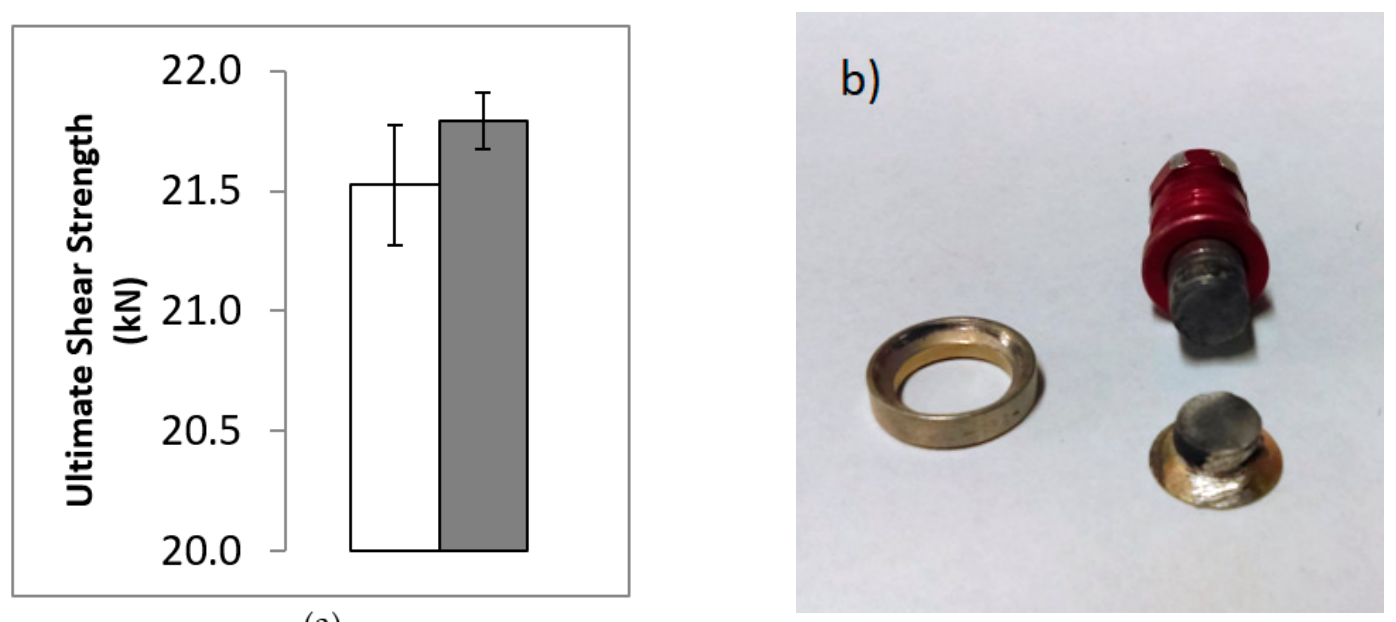

(a)

Figure 5. (a) average static shear strength of fastener pins: Baseline open symbol, collar replacement filled symbol (error bars represent \pm 1 standard deviation); and (b) shear failure of fastener pin (washer shown at left).

\subsection{Static Tensile Strength}

For the static tension tests, ten baseline specimens and ten experimental specimens were tested to failure. Baseline and repeated collar replacement results for static tensile strength are compared in Figure 6a. All measured tensile strength values exceed the published tensile strength of $3000 \mathrm{lb}_{\mathrm{f}}$ 
(16.5 kN) for the HL70-8 collar [14]. All test specimens failed in tear-out of the aluminum collar, as shown in Figure $6 \mathrm{~b}$.

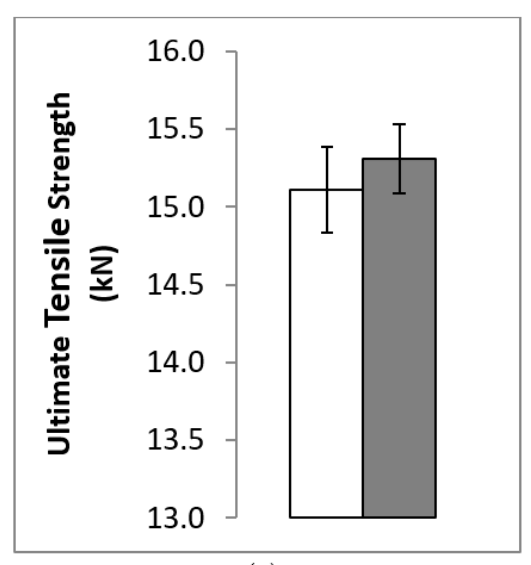

(a)

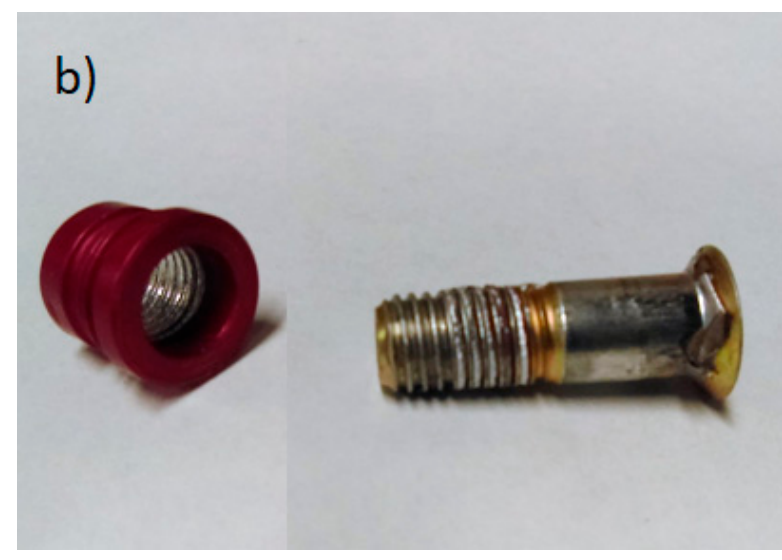

Figure 6. (a) Average static tensile strength of fasteners: Baseline open symbol, collar replacement filled symbol (error bars represent \pm 1 standard deviation); and (b) collar failure of fastener assembly.

\subsection{Shear Fatigue Life}

For the shear fatigue tests, six baseline specimens and five repeated collar replacement specimens were tested to failure in a servo-hydraulic test system. Specimens were subjected to a maximum shear fatigue load, $P_{s}=900 \mathrm{lb}_{\mathrm{f}}(4.0 \mathrm{kN})$ with a load ratio, $R=0$. Baseline and repeated collar replacement test results for shear fatigue life are compared in Figure 7. All test specimens failed in fatigue of the aluminum substrate, as shown previously in Figure $4 \mathrm{~b}$.

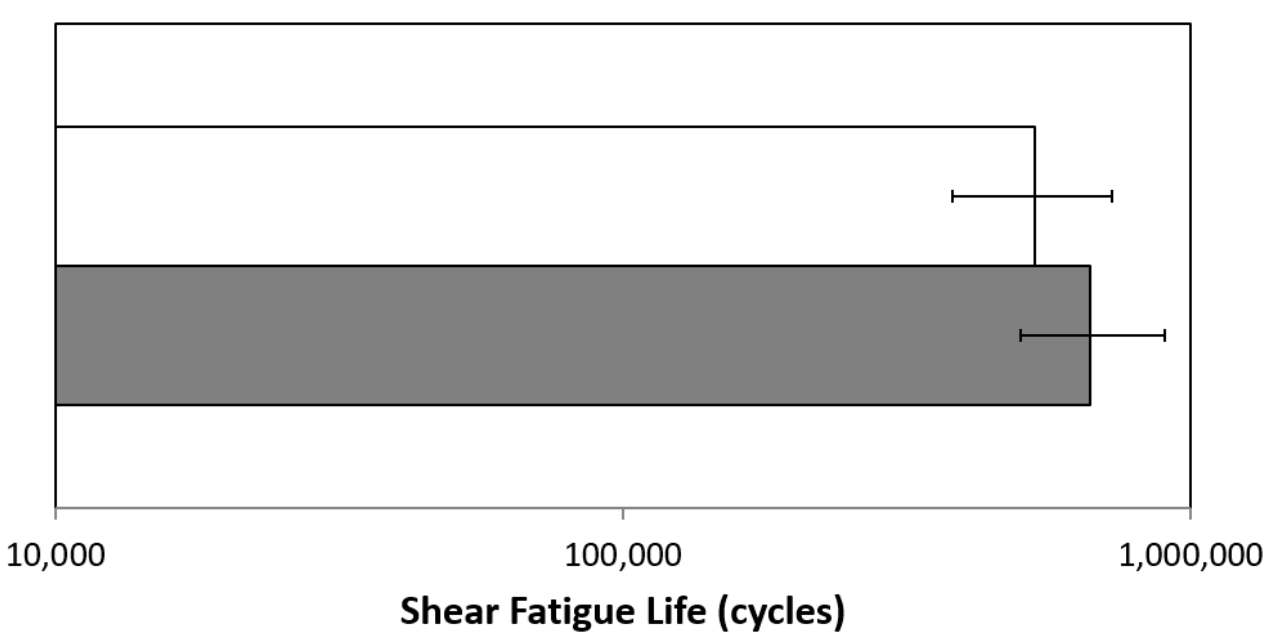

Figure 7. Average shear fatigue life of specimens: Baseline open symbol, collar replacement filled symbol (error bars represent \pm 1 standard deviation, assuming a log-normal fatigue life distribution).

\subsection{Clamping Force}

For each of the collar replacement tests in static shear, static tension, and shear fatigue, the clamping force was estimated from the measured tightening and loosening torques, as described previously.

Clamping force results for the static shear tests are summarized in Figure 8a. A time interval of approximately 30 days elapsed between the initial collar installation and removal (collar 1), and significant time-dependency was evident from the initial clamping force results. This was due to changes in the coefficient of friction between the collar and the substrate due to material relaxation. To mitigate these effects, all subsequent collar installations and removals were conducted without 
delay, eliminating any experimental uncertainty related to time-dependent evolution of the clamping force. Statistical analysis of the results was conducted using experimental data from collars 2 to 5 only, due to the unreliable time-dependent results from the first collar replacement.
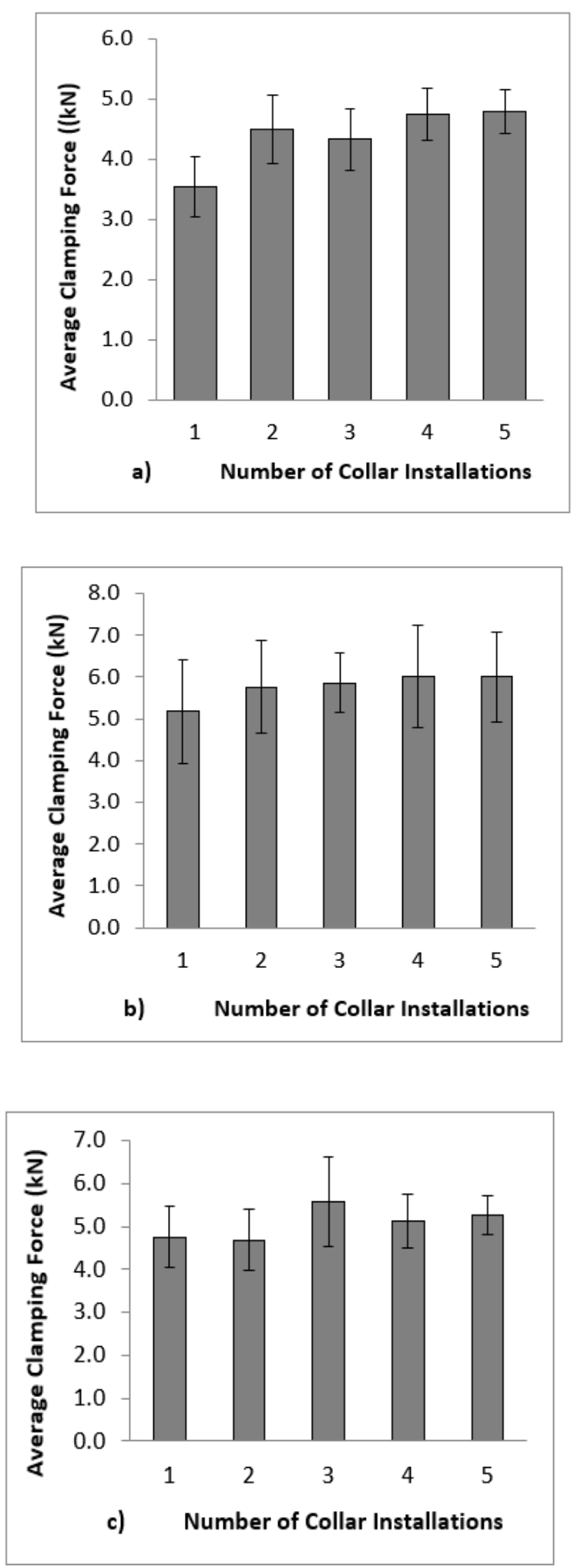

Figure 8. Average clamping force vs. number of collar installations for (a) static shear tests; (b) static tension tests and (c) shear fatigue tests (error bars represent \pm 1 standard deviation). 
Clamping force results for the static tensile tests are summarized in Figure 8b. There were a small number of outliers in the initial collar replacement (collar 1) torque measurements, caused by an unfortunate rotation of the test jig within the test fixture during collar installation. For subsequent collar installations, the tensile test specimens were tightly torqued into the fixture to prevent rotation.

Note that a direct comparison between static shear (Figure 8a) and static tension (Figure 8b) results is not appropriate, given the different compliance of the steel and aluminum substrate of the shear and tensile test specimens. Clamping force results for the shear fatigue tests are summarized in Figure 8c.

\section{Discussion}

\subsection{Static Shear Strength}

All static shear specimens exceeded the minimum published single shear strength of $4650 \mathrm{lb}_{\mathrm{f}}$ $(20.8 \mathrm{kN})$ for the HL19/51-8 fastener pin [13]. Between all specimens, the average ultimate shear strength is $4871 \mathrm{lb}_{\mathrm{f}}(21.7 \mathrm{kN})$, exceeding published values with a percent difference of $8.2 \%$. For the specimens subjected to repetitive collar replacement, a $1.2 \%$ increase in average shear strength is observed, relative to the baseline fastener tests. While this increase is small, it is statistically significant due to the extremely narrow scatter of experimental test results, with a t-test probability value of 0.014 . This value implies only a $1.4 \%$ probability of achieving this result through random statistical variation within the sample. Because there is no clear mechanism to justify an increase in static shear strength of the fastener pin as a result of collar replacement, this result is assumed to represent a statistical anomaly rather than an actual increase in static shear strength.

\subsection{Static Tensile Strength}

All static tensile test specimens exceed the minimum published tensile strength of $3000 \mathrm{lb}_{\mathrm{f}}(16.5 \mathrm{kN})$ for the HL70-8 collar [10]. Between all specimens, the average ultimate tensile strength is $3419 \mathrm{lb}_{\mathrm{f}}$ $(15.2 \mathrm{kN})$, exceeding published values with a percent difference of $14.0 \%$. For the specimens subjected to repetitive collar replacement, a $1.3 \%$ increase in average tensile strength is observed, relative to the baseline fastener tests. This increase is similar in magnitude to the increase seen for static shear strength, but is less statistically significant due to the wider scatter of the observed tensile strength results, with a t-test probability value of 0.092 .

Due to the lower tensile strength of the aluminum collar, as compared to the steel fastener pins, all static tensile test specimens are critical in collar failure. Even with repetitive collar replacement, the static tensile strength of the fastener pin does not become the limiting factor for the overall tensile strength of the fastener. Because there is no clear mechanism to justify an increase in static tensile strength as a result of collar replacement, this result is not believed to represent a meaningful increase in static tensile strength. Regardless, there is no decrease in static tensile strength as a result of repetitive collar replacement for the fasteners in this test.

While static tensile tests are conducted in steel (rather than aluminum) test fixtures due to fatigue and strength requirements, this is seen to be a conservative approach. Estimated clamping force in the steel test specimens is found to be roughly $20 \%$ higher than for the aluminum shear specimens, due to the higher stiffness of the steel substrate. Mechanical damage due to collar replacement should therefore be higher in the steel test fixtures than in the simulated aluminum aircraft structure, providing a conservative estimate for the impact of collar replacement on static tensile strength.

\subsection{Shear Fatigue Life}

For the shear fatigue specimens subjected to repetitive collar replacement, a $1.7 \%$ increase in logarithmic fatigue life is observed relative to the baseline test specimens, representing an increase in average fatigue life from 560,000 to 682,000 cycles. Given the typically observed scatter in fatigue test results, this small experimental increase does not represent a statistically significant variation in the 
fatigue life of the joint, with a t-test probability value of 0.265 . There is no decrease in shear fatigue life as a result of repetitive collar replacement for the fastened joints in this test.

Due to the much lower fatigue strength of the 7075-T6 aluminum substrate, as compared to the $160 \mathrm{ksi}(1100 \mathrm{MPa})$ steel fastener pins, all shear fatigue test specimens failed by fatigue and fracture of the aluminum sheet. The shear fatigue life of the fastener pin does not become the limiting factor for the overall shear fatigue life of the specimen.

The applied $900 \mathrm{lb}_{\mathrm{f}}(4.0 \mathrm{kN})$ constant-amplitude maximum shear fatigue load for these tests is $140 \%$ of the design limit load for the fasteners at Critical Point 16 on the CP140 aircraft [10]. While test load levels are calibrated to ensure that fracture of the specimens occurred within an acceptable number of cycles, the resulting loads are not directly reflective of the actual fatigue strength or behaviour of the simulated aircraft structure.

\subsection{Clamping Force}

For static shear, static tension, and shear fatigue tests, no decrease in average clamping force is observed as a function collar replacement. Between all collar changes, average clamping forces for each test compare relatively well, with single-factor ANOVA probability values of $0.124,0.482$, and 0.280 , for static shear, static tension, and shear fatigue tests, respectively. These results indicate no statistically significant variation in clamping force as a function of collar replacement.

In aluminum substrate, average clamping force of the fastener is found to be $1095 \mathrm{lb}_{\mathrm{f}}(4.9 \mathrm{kN})$ between static shear and shear fatigue tests. For the static tensile tests, conducted in steel fixtures, the average clamping force of $1296 \mathrm{lb}_{\mathrm{f}}(5.7 \mathrm{kN})$ is $18.4 \%$ higher, due to the higher stiffness of the steel substrate. For all tests, estimated clamping force results are highly consistent, with standard deviations well below the $17 \%$ uncertainty expected from [7].

\section{Conclusions}

In this project, Hi-Lok fasteners were subjected to multiple collar replacements and tested to failure under static loading and constant-amplitude fatigue loading. The aim of this research was to determine the effect of repetitive collar replacement on the residual strength and fatigue life of a retained Hi-Lok-type fastener pin. Experimental tests were conducted for static shear, static tension, and shear fatigue. In each case, the results from baseline test specimens were compared to those for identical specimens subjected to five collar replacements, simulating periodic replacement of the fastener collar in a section of fatigue-prone structure for scheduled NDI over the life of an aircraft.

From these tests, static shear results showed no decrease in the ultimate shear strength of the fastener pin as a function of collar replacement. Static tensile results showed no decrease in the ultimate tensile strength of the fastener as a function of collar replacement, with failure of the aluminum collar remaining the critical failure mode. Similarly, shear fatigue results showed no decrease in the shear fatigue life of the fastened joint as a result of collar replacement, with fracture of the aluminum substrate remaining the critical failure mode. For static shear, static tension, and shear fatigue tests, estimated clamping force was highly consistent between specimens and no decrease in clamping force was observed as a function of collar replacement.

The experimental results from this project suggest that deformations and mechanical damage resulting from a limited number of collar replacements over the life of an aircraft do not adversely affect the residual static strength, shear fatigue life, or clamping force of retained fastener pins. Although experimental results support retention of the fastener pin as a safe practice, important practical considerations such as the elevated risk of mechanical damage to the fastener pin and potential corrosion issues linked to repetitive collar removal were outside the scope of this project. 
Author Contributions: D.F.H. performed the research in partial fulfillment of his MEng. degree in aerospace vehicle design with D.L.D. as the project supervisor and administrator. The individual contributions of the authors were as follows: Conceptualization, D.F.H. and D.L.D.; methodology, D.F.H.; validation, D.F.H.; formal analysis, D.F.H.; investigation, D.F.H.; resources, D.F.H. and D.L.D.; data curation, D.F.H.; writing一 original draft preparation, D.F.H.; writing-review and editing, D.L.D.; supervision, D.L.D.; project administration, D.L.D.; funding acquisition, D.L.D.

Funding: Financial support of this research through the Department of National Defence, AERAC and the Natural Sciences and Engineering Research Council of Canada Discovery Grant \# 239174 is gratefully acknowledged.

Conflicts of Interest: The authors declare no conflict of interest.

\section{Nomenclature}

$A=$ dimensionless constant

$D=$ diameter (fastener or hole)

$d_{2}=$ basic pitch diameter of the thread

$d_{i}=$ inner bearing diameter of the nut

$d_{0}=$ outer bearing diameter of the nut

$E=$ elastic modulus

$F=$ clamping force

$F_{s u}=$ ultimate shear stress

$F_{t u}=$ ultimate tensile stress

$p=$ pitch of the threads

$P_{S}=$ shear load

$P_{s u}=$ ultimate single shear strength

$P_{t u}=$ ultimate tensile strength

$T_{\text {on }}=$ tightening torque

$T_{\text {off }}=$ loosening torque

$\beta=$ half-included angle of the threads

$\varepsilon=$ strain

$\mu_{t}=$ coefficient of friction for the thread

$\mu_{e}=$ coefficient of friction for the nut face

\section{Appendix A. Tabulated Experimental Values}

The experimental data recorded for all specimens in this study are included in this Appendix A.

Table A1. Experimental data for static shear strength of fastener pins-Figure 5.

\begin{tabular}{ccc}
\hline \multirow{2}{*}{ Ordered Specimens } & \multicolumn{2}{c}{ Ultimate Shear Strength $\mathbf{( k N )}$} \\
\cline { 2 - 3 } & Baseline Tests & Collar Replacement Tests \\
\hline 1 & 21.15 & 21.64 \\
2 & 21.24 & 21.64 \\
3 & 21.39 & 21.66 \\
4 & 21.45 & 21.74 \\
5 & 21.46 & 21.81 \\
6 & 21.65 & 21.83 \\
7 & 21.67 & 21.85 \\
8 & 21.84 & 21.88 \\
9 & 21.87 & 21.90 \\
10 & - & 21.99 \\
\hline
\end{tabular}


Table A2. Experimental data for static tensile strength—Figure 6.

\begin{tabular}{ccc}
\hline \multirow{2}{*}{ Ordered Specimens } & \multicolumn{2}{c}{ Ultimate Tensile Strength $\mathbf{( k N )}$} \\
\cline { 2 - 3 } & Baseline Tests & Collar Replacement Tests \\
\hline 1 & 14.62 & 14.91 \\
2 & 14.83 & 14.93 \\
3 & 14.83 & 15.26 \\
4 & 15.08 & 15.32 \\
5 & 15.09 & 15.35 \\
6 & 15.24 & 15.37 \\
7 & 15.26 & 15.40 \\
8 & 15.32 & 15.43 \\
9 & 15.40 & 15.50 \\
10 & 15.43 & 15.61 \\
\hline
\end{tabular}

Table A3. Experimental data for shear fatigue life-Figure 7.

\begin{tabular}{ccc}
\hline \multirow{2}{*}{ Ordered Specimens } & \multicolumn{2}{c}{ Shear Fatigue Life } \\
\cline { 2 - 3 } & Baseline Tests & Collar Replacement Tests \\
\cline { 2 - 3 } & Cycles & Cycles \\
\hline 1 & 299,375 & 477,080 \\
2 & 459,220 & 540,172 \\
3 & 478,433 & 712,686 \\
4 & 579,463 & 833,426 \\
5 & 679,867 & 846,124 \\
6 & 864,655 & - \\
\hline
\end{tabular}

Table A4. Experimental data for clamping force for static shear tests-Figure 8a.

\begin{tabular}{cccccc}
\hline \multirow{2}{*}{ Ordered Specimen } & \multicolumn{5}{c}{ Estimated Clamping Force (kN) } \\
\cline { 2 - 6 } & Collar 1 & Collar 2 & Collar 3 & Collar 4 & Collar 5 \\
\hline 1 & 2.16 & 3.61 & 3.37 & 4.09 & 4.27 \\
2 & 2.48 & 3.69 & 3.74 & 4.26 & 4.44 \\
3 & 3.17 & 4.19 & 3.97 & 4.55 & 4.49 \\
4 & 3.51 & 4.33 & 4.19 & 4.55 & 4.55 \\
5 & 3.51 & 4.38 & 4.46 & 4.75 & 4.68 \\
6 & 3.61 & 4.75 & 4.53 & 5.03 & 4.75 \\
7 & 3.66 & 4.76 & 4.55 & 5.10 & 5.07 \\
8 & 3.72 & 4.79 & 4.59 & 5.15 & 5.10 \\
9 & 4.61 & 5.01 & 4.85 & 5.35 & 5.16 \\
10 & 5.10 & 5.45 & 5.05 & - & 5.40 \\
\hline
\end{tabular}

Table A5. Experimental data for clamping force for static tensile tests-Figure $8 \mathrm{~b}$.

\begin{tabular}{cccccc}
\hline \multirow{2}{*}{ Ordered Specimen } & \multicolumn{5}{c}{ Estimated Clamping Force (kN) } \\
\cline { 2 - 6 } & Collar 1 & Collar 2 & Collar 3 & Collar 4 & Collar 5 \\
\hline 1 & 4.18 & 3.81 & 5.03 & 4.18 & 4.64 \\
2 & 4.36 & 4.90 & 5.18 & 4.88 & 4.79 \\
3 & 4.93 & 5.03 & 5.32 & 5.33 & 4.90 \\
4 & 5.03 & 5.23 & 5.48 & 5.48 & 5.67 \\
5 & 5.33 & 5.79 & 5.80 & 5.77 & 5.72 \\
6 & 5.70 & 5.95 & 5.95 & 5.80 & 6.39 \\
7 & 6.67 & 6.20 & 5.99 & 6.34 & 6.45 \\
8 & - & 6.42 & 6.12 & 6.82 & 6.62 \\
9 & - & 6.45 & 6.24 & 6.93 & 6.82 \\
10 & - & 7.86 & 7.49 & 8.57 & 8.05 \\
\hline
\end{tabular}


Table A6. Experimental data for clamping force for shear fatigue tests-Figure 8c.

\begin{tabular}{cccccc}
\hline \multirow{2}{*}{ Ordered Specimen } & \multicolumn{5}{c}{ Estimated Clamping Force (kN) } \\
\cline { 2 - 6 } & Collar 1 & Collar 2 & Collar 3 & Collar 4 & Collar 5 \\
\hline 1 & 4.29 & 3.52 & 4.18 & 4.39 & 4.90 \\
2 & 4.41 & 4.53 & 5.28 & 4.68 & 5.05 \\
3 & 4.64 & 4.88 & 5.65 & 5.13 & 5.07 \\
4 & 4.75 & 5.20 & 5.70 & 5.48 & 5.23 \\
5 & 5.68 & 5.30 & 7.11 & 5.92 & 6.02 \\
\hline
\end{tabular}

\section{References}

1. Lisi Aerospace. Hi-Lok Collar. Available online: http://www.lisi-aerospace.com/products/fasteners/internallythreaded/collars/Pages/nut-hi-lok.aspx (accessed on 5 March 2019).

2. Hi-shear Corporation. Hi-Lok/Hi-Tigue Fastening Systems: Installation Instructions; Hi-Shear Corporation: Torrance, CA, USA, 1991.

3. C-12-140-012/TR-001-Repair Instructions-CP140 Aurora/CP140A Arcturus-Structural Volume 1.

4. Fahr, A.; Wallace, W. Aeronautical Applications of Non-Destructive Testing; DEStech Publications, Inc.: Lancaster, PA, USA, 2014.

5. Jones, R.; Molent, L.; Pitt, S. Understanding Crack Growth in Fuselage Lap Joints. Theor. Appl. Fract. Mech. 2008, 49, 38-50. [CrossRef]

6. Director General of Aerospace Engineering and Project Management. RMC 2005-007-SLA, -DGAEPM 482147 Request for Research, Scientific, and Technical Assistance from Royal Military College; DGAEPM: Ottawa, ON, Canada, 2006.

7. Heshavanarayana, S.; Smith, B.L.; Gomez, C.; Caido, F. Fatigue-Based Severity Factors for Shear-Loaded Fastener Joints. J. Aircr. 2010, 47, 81-191.

8. Li, C.; Su, H. The Influence of Pre-tension Load in the Composite Laminate Fastener Joint During Repeated Tightening. In Proceedings of the 21st International Conference on Composite Materials, Xi'an, China, 20-25 August 2017.

9. IMP Aerospace. DWG \# 939529-CA40; IMP Aerospace: Enfield, NS, Canada, 2010.

10. Lockheed Martin Corporation. STP52-726; Lockheed Martin Corporation: Bethesda, MD, USA, 2010.

11. LISI Aerospace. HL19 Hi-Lok Pin Data Sheet. Available online: http://www.lisi-aerospace.com/products/ Pages/Fasteners-Catalog.aspx (accessed on 5 March 2019).

12. Eccles, W. A New Approach to the Checking of the Tightness of Bolted Connections; Lubrication, Maintenance, and Tribotechnology; Paper Number: L144056; LUBMAT 2014: Manchester, UK, 2014.

13. Eccles, W. A New Approach to the Tightness Checking of Bolts. Fastener + Fixing Magazine; Issue 90. 2014. Available online: http://boltscience.com/pages/a-new-approach-to-the-tightness-checking-of-bolts.pdf (accessed on 5 March 2019).

14. LISI Aerospace. HL70 Hi-Lok Collar Data Sheet. Available online: http://www.lisi-aerospace.com/products/ Pages/Fasteners-Catalog.aspx (accessed on 5 March 2019).

(C) 2019 by the authors. Licensee MDPI, Basel, Switzerland. This article is an open access article distributed under the terms and conditions of the Creative Commons Attribution (CC BY) license (http://creativecommons.org/licenses/by/4.0/). 